\title{
"A Simbologia de Procusto e a Normalização do Plano Estadual de Educação - PE - 1988-1991"
}

O cenário sócio-político e pedagógico brasileiro dos anos 80 foi influenciado por temas como: "exclusão" e "cidadania". Células semânticas que passaram a compor a gramática discursiva dessa década. Frente a esse panorama, centramos a nossa análise na Política educacional do Estado de Pernambuco (1988-1991), que propunha resgatar a cidadania como uma de suas metas básicas, estendendo os seus raios de ação ao universo do portador de deficiência.

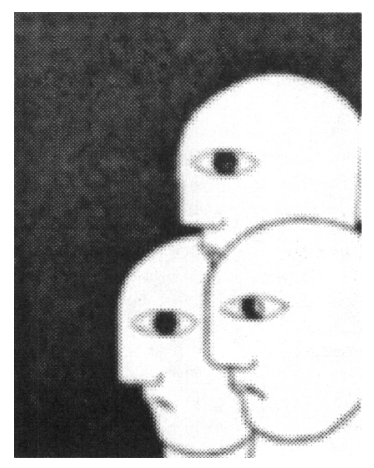

Fabiana Wanderley de S. Moreira psicóloga, professora universitória, consultora pedagógica emestroem Educợcōo pelo UFPE.

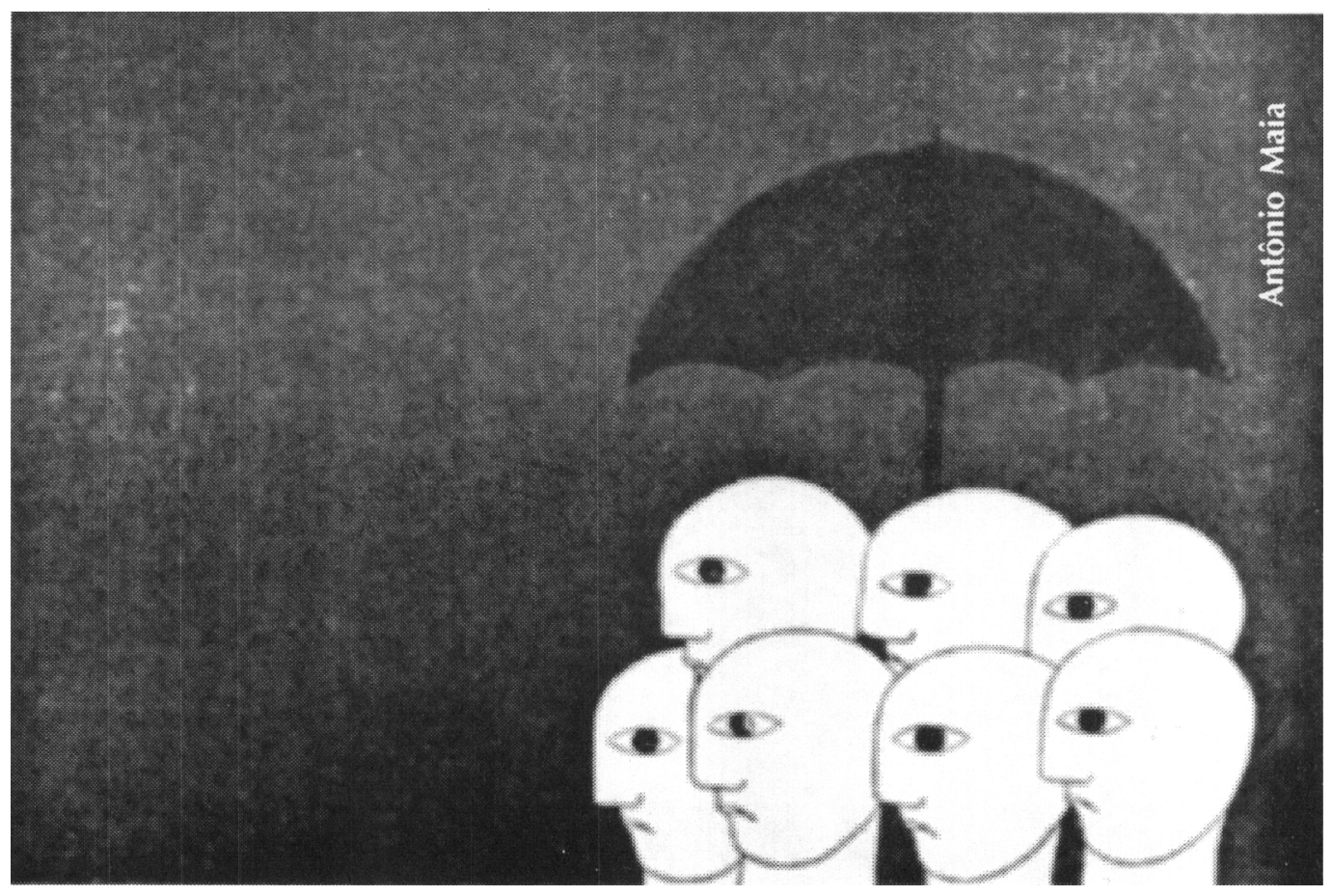

Este artigo traz para o cenário acadêmico uma discussão pioneira: articular a lenda de Procusto e o Plano Estadual de Educação, formulado no período de 1988-1991, no Estado de Pernambuco. Essa temática foi construída ao longo de três anos de mestrado na UFPE, a partir do estudo intitulado "Expressões e silêncios do discurso CidadaniaDeficiência Mental - uma abordagem históricodiscursiva do "Plano Estadual de Educação PE 1988/1991".

Esse estudo procurou mapear o discurso político-pedagógico que, na formulação do
Plano Estadual de Educação de Pernambuco (1988-1991), orientou uma articulação entre deficiência mental e cidadania, no tocante à educação especial. O estudo visava a apreender os elementos dinâmicos das políticas e das práticas discursivas sobre a educação para portadores de deficiência no Brasil e retraçar o sentido da intervenção estatal no âmbito da educação especial, com um enfoque na política defendida nos anos 80, especialmente em Pernambuco (19881991), que tentava articular, pioneiramente, Cidadania-Trabalho-Escola-Deficiência mental. 
Numa perspectiva mais verticalizada, acreditamos que a figura de Procusto não é desconhecida do meio acadêmico e literário. Segundo a lenda grega Procusto, era um bandido que oferecia sua hospitalidade aos viajantes perdidos. Ele deitava-os sobre uma cama de ferro e, se os corpos fossem mais longos do que a cama, ele cortava-os até que coubessem nos limites do ferro. Se fossem mais curtos, esticava-os violentamente. Era, por assim dizer, um normalizador.

Tomando como referência a simbologia de Procusto, analisemos a realidade do nosso estudo: a política de educação especial delineada no governo de Arraes no período de 1988-1991. Será que poderíamos estabelecer pontos de convergência entre a lenda de Procusto e as propostas e diretrizes norteadoras desse governo? Revisitemos essas propostas.

A gestão Arraes propunha resgatar a cidadania como uma de suas metas básicas e visualizava a educação não só como "espaço escolar", mas como universo complexo de relações entre os indivíduos. As ações eram direcionadas para garantir o acesso da população a uma escola pública que deveria ser qualificada e democrática. Por reconhecêla autoritária e reprodutora das contradições sociais, ela deveria transformar-se num elemento constituinte dos direitos de cidadania, extensivo aos portadores de deficiência. Nessa perspectiva, a proposta do Plano Estadual desejava que aos deficientes mentais fosse atribuído o estatuto de diferentes e que sua integração à vida social ordinária se processasse não na ordem de uma esfera profissional restrita ou precária, mas na de uma cidadania crítica e ativa.

O objetivo da nossa pesquisa, portanto, foi analisar o discurso e os procedimentos práticos canalizados para a deficiência mental, tomando como referência básica o "Plano Estadual de Educação - PE 1988/1991 (P.E.E. PE 1988/1991), cotejado com as açōes desenvolvidas em uma escola pública especial e em instituições que atenderam a uma clientela portadora de deficiência na cidade do Recife.
Podemos empreender uma análise crítica de nossa investigação assentada em três grandes eixos: o teórico, o conceituale o instrumental.

Por tratar-se de um estudo interdisciplinar, no eixo teórico, utilizamos referenciais do campo da psicologia e da pedagogia, que foram fundamentais para a compreensão das estratégias, propostas, diretrizes psicopedagógicas e práticas discursivas que se voltaram para promover a inserção dos alunos portadores de deficiência numa ordem de cidadania real, num determinado momento da história da educação especial pernambucana. A nossa crença numa pesquisa interdisciplinar, para melhor compreender o fenômeno estudado, repousa no fato de que a própria ciência hoje não pode isolar-se em compartimentações e nem se restringir à rigidez de estruturas conceituais unívocas, ao contrário, impōe-se a plurivocidade, o alargar fronteiras entre as disciplinas, o permear e entremear saberes.

No eixo conceitual, trabalhamos com o conceito-chave de episteme, de Michel Foucault. Uma episteme, na visão foucaultiana, corresponde ao a priori histórico que dá sustentação a práticas discursivas e discursos num determinado campo do saber. Como as epistemes são camadas conceituais que sustentam vários campos de saber $\mathrm{e}$ correspondem a diferentes épocas no pensamento ocidental, a análise histórica deve "desterrá-las" - e daí o modelo arqueológico de Foucault. No nosso caso, tentamos "desterrar" as camadas conceituais a respeito do saber sobre o deficiente mental e sua articulação com a cidadania.

No eixo instrumental, quanto à metodologia, após realizarmos mapeamento sócio-histórico sobre a institucionalização da educação especial brasileira e pernambucana, centramos o nosso foco de análise na realidade de Pernambuco do período 1988-1991, que tentava articular, pioneiramente, cidadaniatrabalho-escola-deficiência mental. Nesse 
período, observávamos a existência de uma gramática ou arquitetura discursiva que dispunha, sob um mesmo denominador comum, excluído/situações de exclusão distintas entre si, isto é, as diferenças de natureza econômica, cultural e psicológicas eram reduzidas a um bloco único, o dos excluídos. Essas constatações nos levaram a questionar a possibilidade e a forma de inserção dos deficientes mentais no elenco dos excluídos e o respaldo institucional para promover a integração desses sujeitos a uma ordem de cidadania real. Essas indagações foram fúndamentais para a construção do instrumental de abordagem (qualitativa e de caráter exploratório) do universo da nossa pesquisa (instituições e escola especial para portadores de deficiência mental da cidade do Recife).

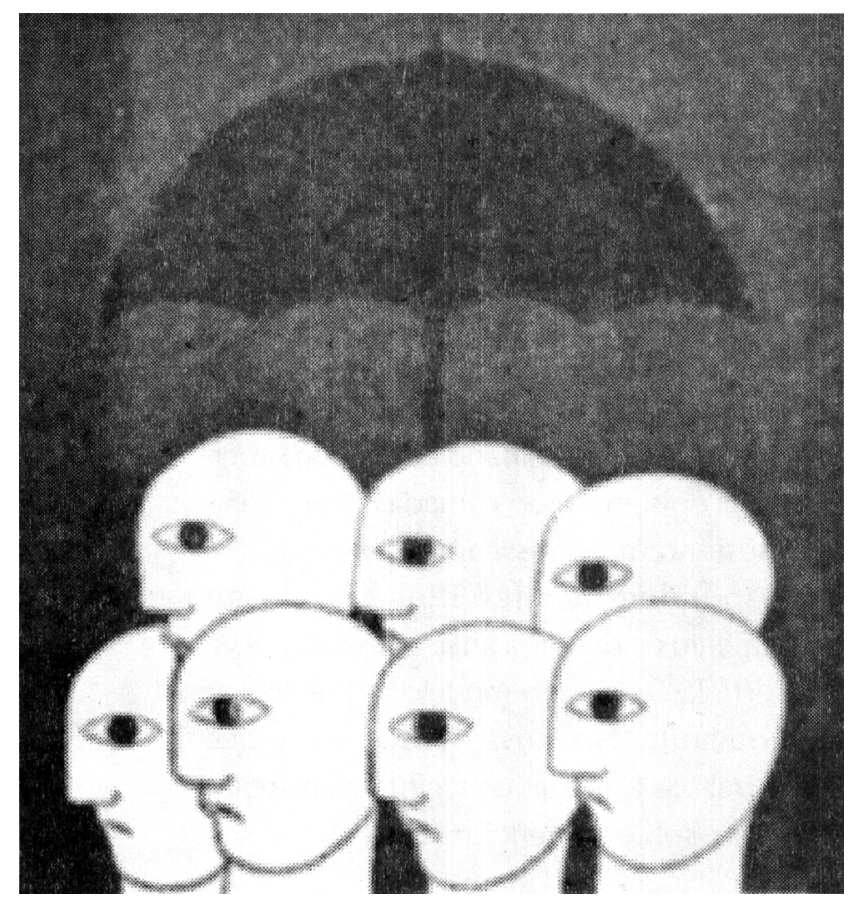

Quanto à análise do material estudado, utilizamos como ferramenta a Análise do Discurso, cujo objeto específico, como nos diz Orlandi (1986:107) é o discurso e não a língua, e a unidade de análise é o texto (e não o signo ou a frase), considerado no seu aspecto qualitativo, como unidade significativa da linguagem em uso, de natureza pragmática. Por ser uma abordagem nova em relação ao Estruturalismo (Saussure) e ao Gerativismo (Chomsky), a Análise do Discurso é considerada ainda como ponto de vista da ciência lingüística. $O$ sujeito (produtor de linguagem e produzido por ela), nesse contexto teórico-conceitual, não é entendido como ser a-histórico, mas visto, sobretudo, "em sua relação necessária com a ideologia, como tenso, contraditório, obscuro", características que se refletem no próprio discurso, como explica Lívia Suassuna (1995:101). Dessa forma, a construção de qualquer texto sempre é realizada a partir das múltiplas imagens que o sujeito tem sobre o contexto, as quais the permitem falar sobre lugares distintos e a interlocutores diversos.

Sob essa ótica de referências, a análise semântica de um determinado discurso implica, essencialmente, que ele seja visto em sua relação com o contexto que permitiu sua elaboração. Isso significa que existe, quanto ao sentido, uma relação necessária entre o dizer ou falar e as condições de produção desse falar ou dizer. Por serem históricas, essas condições compreendem os mecanismos lingüísticos e as normas sociais, os quais se aderem aos elementos nãolingüísticos, permitindo que o discurso seja a conseqüência de um processo no qual estão contidos também o lugar social e as intenções dos interlocutores no fazer discursivo. Não podemos deixar de aproximar os pressupostos da análise do discurso às noções de episteme foucaultiana. Não podemos esquecer também que no discurso vamos encontrar apenas uma representação da realidade, entre as possíveis, sendo o seu sentido múltiplo, como são múltiplas as suas marcas e significaçōes, que são consideradas as do próprio texto e podem transformar-se em verdadeiros símbolos da realidade. É essa consciência representacional de um texto oficial que norteou as nossas intenções interpretativas, direcionando-nos na tentativa de desvelar as concepções de "cidadania", "deficiência mental" e da relação cidadania-deficiência menta I contidas no Plano Estadual de Educação 1988-1991. Para isso, os depoimentos dos atores envolvidos em 
nosso estudo (29, ao todo) nos deram uma visão de como e por que, em Pernambuco, o discurso cidadania-deficiência mental foi possivel e ganhou estatuto institucional.

Esses depoimentos, no entanto, revelaramnos um sentimento de impotência não apenas em relação à procariedade das condições materiais em que funciona o sistema educacional, mas, sobretudo, no que diz respeito à virada discursiva implementada na educação especial no período estudado: passagem de um discurso medicalizante/ psicolgizante para um discurso eminentemente político-pedagógico. Aquele momento era permeado por palavras de ordem que duramente lograram êxito lingüístico e político, sendo abraçadas e difundidas pelos educadores brasileiros, compondo, assim, uma espécie de dicionário pedagógico dos anos 80 , corrente e consensualizado: democracia, exclusão, cidadania, hegemonia popular, sociedade civil, pluralismo... Nesse contexto, os deficientes mentais eram alçados à condição de cidadãos ativos (em potencial), bastando, para tanto, um trabalho de reeducação da sociedade inclusiva que a preparasse para acolhê-los como membros iguais e singulares.

Podemos dizer, então, que falar de cidadania ativa e interveniente é construir um discurso extremamente sedutor, com a vantagem de obter adesões fáceis porque mobiliza esferas de desejo reprimido, de fantasia de reconciliação, o que integra aquilo que está separado. Aqui, reaparece o nosso Procusto, figura lendária, que, mesmo oferecendo sua hospitalidade aos viajantes, atuava "esticandoos" e "cortando-os", ou seja, enquadrandoos e normalizando-os. Façamos dele o representante dos que se utilizam de projetos assentados na re-educação. Por analogia, podemos dizer que a política educacional (de reeducaçāo) do período 1988-1991, surgida num governo dito "popular" e com um discurso político-pedagógico que orbitava em torno da "cidadania das classes populares", também tinha um caráter normalizador. Sua atuação procurava, a todo custo, como diz
Brayner (1995), estender para as camadas populares, "(...) as aquisiçōes sociais, culturais e políticas de uma sociedade moderna".

Dentro dessa perspectiva, esse governo precisava falar em cidadania para todos os excluídos, inclusive os DMs, transformando-os num objeto "pedagogizável" e "politizável", constituindo-os discursivamente como esse objeto: A política do governo Arraes corporificava o esforço da moderna sociedade democrática de integração desses sujeitos, intrinsecamente diferentes, ao meio social.

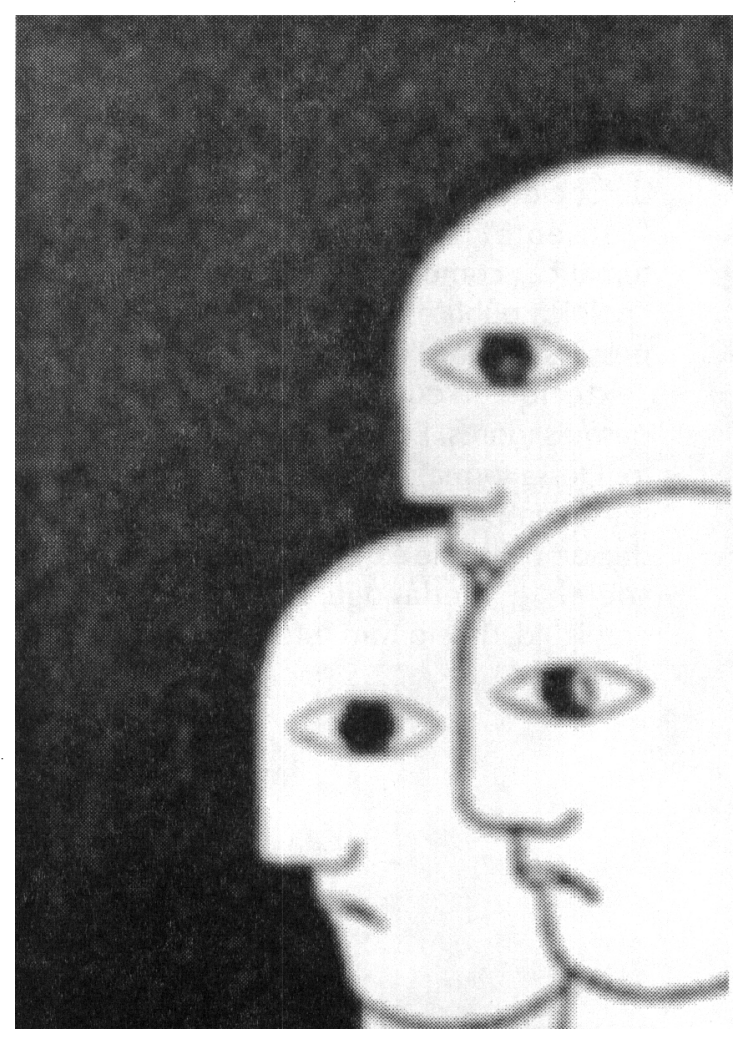

Atuava, portanto, exercendo um poder normalizador sobre esses indivíduos, à medida que tentava submetê-los a um mainstream (corrente principal) do pensamento e a um vocabulário pedagógico dos anos 80 , especialmente influenciado por teóricos como Gramsci. Nesse contexto interpretativo, não seria leviandade afirmarmos que, no fundo de um ideal humanista e democrático, residia um pulso voluntarista, o qual, não raras vezes, esbarrou num desagradável "princípio de realidade", para usar uma terminologia freudiana. 


\section{"toda a palowra, enquanto o individuo nela se acha implicado, é discurso do Outro, parte do \\ Outro". \\ Mannoni(1970)}

Quanto às contribuiçōes do estudo, acreditamos que, de forma mais ou menos verticalizada, conseguimos apreender os códigos de referência, valores e atitudes que circunscreveram as políticas educacionais dos anos 80, voltadas para o estudo do "diferente" (DM) e para as questões de sua cidadania.

Quanto às limitações do estudo, é possivel afirmar que, mais uma vez, não foi abandonado o terreno científico, que exclui, pela sua própria linguagem e propósitos de sistematização e análise, o indivíduo sobre o qual se fala, pois, como nos diz Mannoni (1970), "toda a palavra, enquanto o indivíduo nela se acha implicado, é discurso do Outro, parte do Outro". Nesse sentido, podemos dizer que o nosso próprio texto trata do deficiente a partir da nomeação, da localização teórica e discursiva de um objeto de sociedade e cultura, mas ele não está "presente" senão como campo, como temática, como objeto de avaliação, como "política pública". Ele não pode me ouvir. E, nesse sentido, "estudá-lo" é tratá-lo como "exterior", como o outro de nós, pesquisadores. Em poucas palavras, é excluílo. Dessa forma, a própria gramática gerativa que rege o discurso sobre o deficiente, ao decidir o que ele é e como deveria ser tratado social e pedagogicamente, revela a ambigüidade e o tom tutelar de um discurso "cidadão".
Assim, podemos perceber que investigar a história discursiva da deficiência mental, a partir dos supostos teóricos que escolhemos, parece nos mostrar que, mais do que a existência de sujeitos desviantes da normalidade (o que também já constitui um discurso), essa história é uma constante apropriação por uma ordem (psiquiátrica, psicológica, pedagógica, política) do objeto "deficiência mental", re-instituindo-se a cada passo. A sua subtração do universo específico do discurso psiquiátrico e sua anexação ao domínio do pedagógico proporcionaram, ao nosso ver, a possibilidade de que aquele "objeto" ganhasse uma dimensão política inaudita numa cultura em que o pedagógico é compreendido como epifenômeno do político; fazer da deficiência mental campo de re-educação é permitir, rapidamente, o seu trânsito para a "intervenção" (política) na realidade.

Por outro lado, não queremos e não podemos invalidar a relevância e pertinência de estudos como este. Principalmente pela consciência do seu caráter interdisciplinar, imprescindivel às decisões institucionais, aos debates e pesquisas científicas sobre a educação especial, convidamos interlocutores distintos a entrar em cena para instigar, tensionar e ampliar o discurso da "diferença", para inaugurar uma nova fase de observação e de respeito às subjetividades.

Fhiana Wandertey de S. Moreira

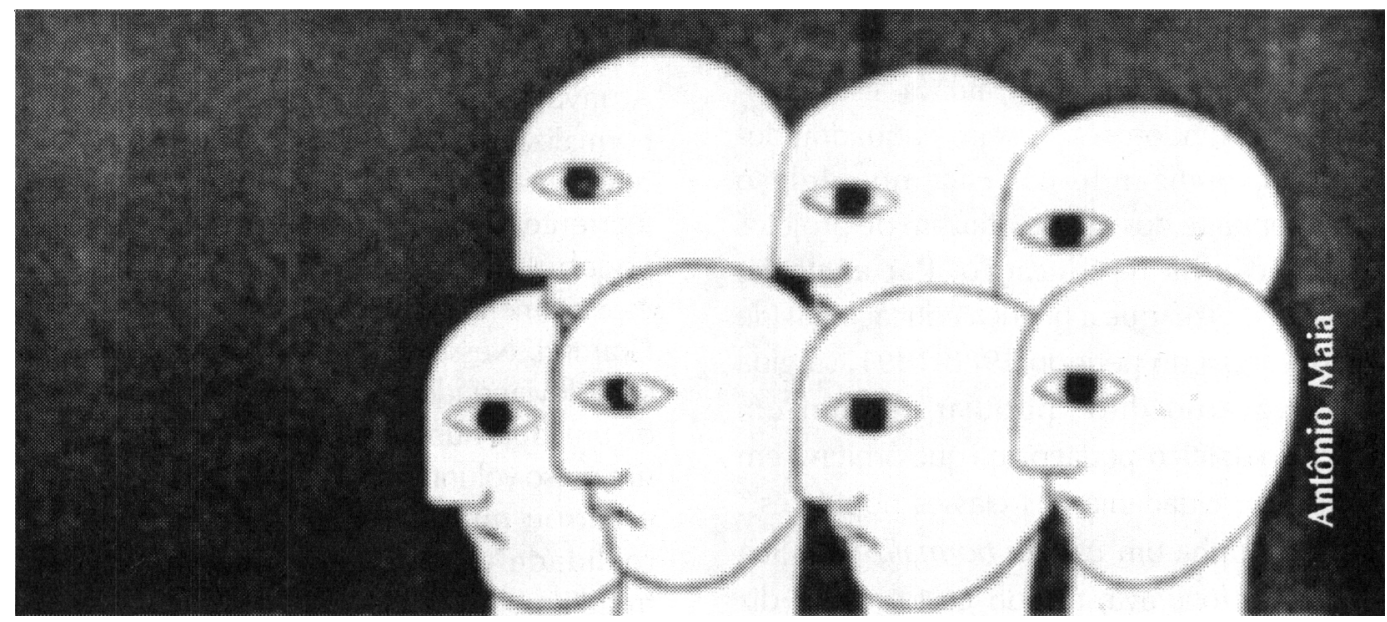


Aguiar, C. L. B. de, et alli., (1991). “Proposta Pedagógica para a Área de Deficiência Mental". Cadernos de Educação Especial. Série Ensino, Recife.

Brayner, E.H. A. (1995).“ Sobre 'Cidadania', Educaçāo, Competência”. Ensaios de Crítica Pedagógica. Campinas: Autores Associados.

Fonseca, Victor de., (1987). Educação Especial. Porto Alegre: Artes Médicas.

Jannuzzl, G.S.M. História da Educação no Brasil: (1876 - 1935). Campinas/Unicamp, 1985. Tese de Doutoramento em Educação.

Longman, L. V.(1991. “Algumas Concepçōes Norteadoras da Educação Especial em Pemambuco". Cadernos de Educaçăo Especial. Série Ensino, Recife.
Mazzotta, M.J.S.(1996). Educaçăo Especial no Brasil: História e Poltiticas Públicas. São Paulo: Cortez.

Orlandi, E. (1983). Linguagem e seu Funcionamento: As formas do discurso. São Paulo: Brasiliense.

Pernambuco.. Plano Estadual 1988/1991. Recife: Inojosa. 1988.

Rosa, E. C. de S. , (1990) Aluno Portador de Deficiência: Problema Médico-Pedagógico ou Conquista da Cidadania? - A Educação Especial em Pernambuco. Tese de Mestrado, UFPE, Recife..

Suassuna, L. (1995) .Ensino da Língua Portuguesa: uma abordagem pragmática. Campinas: Papirus,

Referências bibliográficas 